\title{
PH90
}

\section{Museo de Huelva: récord histórico de visitantes}

El Museo de Huelva, institución fundada en 1920, pero sin sede definitiva hasta 1973, a lo largo de su historia ha superado numerosas dificultades. Desde hace tres años, y debido fundamentalmente al trabajo de un equipo de profesionales comprometidos con la realidad social de la institución, las visitas al museo han registrado una tendencia positiva llegando a alcanzar un récord histórico en 2015, con un total de 38.000 usuarios. Ahora, cuando se acerca el centenario de la institución, algunos de los objetivos planteados, además de mantener el incremento en el número de visitas, son tender puentes de colaboración con el resto de agentes culturales; la renovación de su gabinete pedagógioco y de los recursos didácticos; y la realización de un plan museológico como punto de partida a una nueva etapa de modernización.

Pablo S. Guisande Santamaría | director del Museo de Huelva

URL de la contribución <www.iaph.es/revistaph/index.php/revistaph/article/view3836>

En los últimos tres años el museo de Huelva ha duplicado sus visitas; esto es, ha aumentado un $100 \%$ el número de visitantes, para alcanzar la cifra de 38.000 usuarios el pasado 2015, lo que supone el récord histórico. Este dato se hace aún más relevante si tenemos en cuenta que los presupuestos actuales son hasta cinco veces inferiores a los de hace unos años.

Sin duda vivimos en una época en la que el ingenio es imprescindible y, en museos de ciudades medias como Huelva, las programaciones no soportan grandes exposiciones. Se precisan estrategias novedosas para configurar una oferta cultural atractiva al mismo tiempo que rigurosa en cuanto a sus contenidos. Afrontando la coyuntura actual, la respuesta es una gestión responsable dirigida a la optimización de recursos, tratando de desarrollar programaciones que interesen a los onubenses, que ayuden a entender la historia haciendo posible el acceso de todos al patrimonio, desarrollando el potencial que posee el museo para la identidad local, y como recurso turístico generador de riqueza.

Tras la democratización de la cultura en el último cuarto del siglo XX, el siglo XXI asiste al consumo de masas y el museo debe responder con nuevas formas de relación con la sociedad. En este sentido, desacralizar las bellas artes y desmitificar la arqueología se hacen imprescindibles, lo que implica volver a la escala humana, mediante recursos que apelen a los aspectos emocionales del patrimonio como punto de partida del conocimiento. Aquí las nuevas tecnologías dan paso a un nuevo modo de comunicación global basado en las redes sociales en el que la institución se encuentra inmerso, siendo el museo provincial de Andalucía con más seguidores en Facebook, además de contar con cuentas en Twitter, Youtube e Instagram.

Tender puentes de colaboración con el resto de agentes culturales de la ciudad y la provincia es una de las claves para generar la sinergia necesaria para que proyectos interesantes vean la luz. En este sentido, destacan los proyectos comunes con el Área de Arqueología de la Universidad de Huelva, dando lugar a exposiciones como la actual De Tarteso a Itucci. Arqueología en el Campo de Tejada, que se encuadra en una línea de trabajo prioritaria, que es seleccionar yacimientos arqueológicos singulares que la sociedad desconoce para presentarlos de modo didáctico con materiales de los propios fondos, como ya se hiciera el pasado año con Saltés, en las Puertas del Paraíso, exposición dedicada a la memoria de la que fuera directora del Museo de Huelva Juana Bedia. Del mismo modo, se está llevando a cabo el programa Los Pueblos de Huelva en el Museo, destinado a dar a conocer el patrimonio cultural de diversas localidades de Huelva, enfatizando el carácter provincial del museo, tendiendo lazos de colabora- 


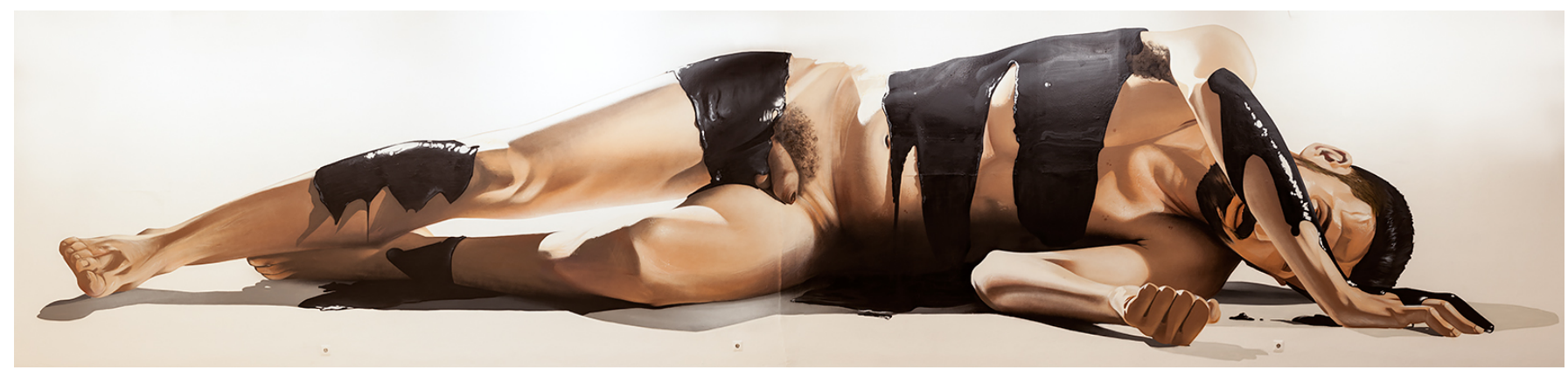

Exposición Selfiel, del artista urbano onubense Man-o-Matic

ción con instituciones locales y potenciando el concepto de territorio de nuestro patrimonio cultural. Ejemplo de ello es la exposición, de septiembre de 2016, El Cerro de Andévalo, realizada en colaboración con el Museo Etnográfico y el Ayuntamiento de dicha localidad.

En cuanto al arte contemporáneo los últimos años han supuesto la colaboración con la Diputación Provincial de Huelva en la gestión de la Sala siglo XXI, cuya programación se destinaba en exclusiva a la creación actual, con diez exposiciones anuales, entre las que podemos destacar Selfiel del artista urbano onubense Man-o-Matic, que supuso una arriesgada apuesta, ya que fue la primera muestra de arte callejero con técnica de espray en el museo, con un rotundo éxito de público y crítica. Esta iniciativa puede servir de ejemplo de una actitud decidida a salir de la denominada zona de confort para explorar nuevas propuestas destinadas a superar la concepción estática del museo tradicional.

Uno de los problemas endémicos del Museo de Huelva es la falta de espacio, pero como respuesta se construyen diferentes discursos que propicien nuevas visiones e interpretaciones, para que las piezas de los fondos vean la luz. En este sentido, se han potenciado las visitas a las zonas de reserva, tanto de arqueología como de bellas artes, con el objetivo de compensar dicha limitación espacial y dar a conocer a los usuarios los métodos de trabajo, así como la cantidad y calidad de nuestras colecciones. La respuesta de la sociedad a esta iniciativa ha sido espectacular, y se ha convertido en habitual debido a la gran demanda, conformando el programa Museo oculto.
Las colaboraciones a nivel internacional se han traducido en la presencia de algunas piezas relevantes de la colección en museos y exposiciones importantes, como el lienzo La muerte del torero de Daniel Vázquez Díaz en el Museo de las Culturas Taurinas de Nimes (Francia). Pero sin duda el préstamo más importante en cuanto a su dimensión internacional ha sido el de dos jarros tartésicos de la necrópolis de la Joya (Huelva) que formaron parte de la exposición De Asiria a Iberia del Metropolitan Museum de Nueva York, donde se dieron cita los museos más importantes del mundo, además de piezas tan significativas como el tesoro del Carambolo del Museo Arqueológico de Sevilla.

Como retos actuales encontramos la renovación del gabinete pedagógico y de los recursos didácticos; la modernización y sistematización de los inventarios y catálogos tanto de arqueología como de bellas artes; el diseño de un plan de accesibilidad para un edificio hoy obsoleto que atienda a las necesidades de cualquier tipo de diversidad funcional; llevar a cabo un plan integral de conservación y restauración; y la realización de un plan museológico como punto de partida a una nueva etapa de modernización. 